\title{
Influence of digital application on the development of public ceramics
}

\author{
Xiaoping Zhou ${ }^{1}$ Yanmin Liu ${ }^{2 *}$ Lian Xiaobo ${ }^{3}$ Peng Zixuan ${ }^{4, \text { a }}$ Chen zhihong ${ }^{5, b}$ \\ ${ }^{1}$ College of Architecture and Civil Engineering, Xiamen Institute of Technology, Xiamen, China \\ ${ }^{2 *}$ College of Architecture and Civil Engineering, Xiamen Institute of Technology, Xiamen, China \\ ${ }^{3}$ College of Architecture and Civil Engineering, Xiamen Institute of Technology, Xiamen Fujia, 361021, China \\ ${ }^{4}$ Meilie district advanced school, Sanming City, China \\ ${ }^{5}$ Meilie district advanced school, Sanming City, China
}

\begin{abstract}
Since the 1980s, China's public ceramic art has been greatly expanded and improved due to the influence of multiple western art trends, the conscious promotion of public awareness, and the imbalance between economic development and spiritual demands. With the advent of the digital era, digital application has become increasingly mature in the field of public ceramics. Digital application has a profound impact on the modeling, production process, process control and ceramic printing of public ceramics.
\end{abstract}

\section{Introduction}

With the development of urbanization in China, the demand of urban "cultural decoration" has set off a vigorous "public art" movement in China. In recent years, ceramic materials have become a new form of art space. Rodin said that "the life of art is born out of materials." Ceramic art has become a charming art field with its unique quality. The free clay, the beauty of glaze and the beauty of firing, as well as the emotional blend of man, clay and fire, make ceramic art have an inherent feature suitable for communication and acceptance. Entering the vast public space and closely connected with social life is a challenging new development direction of contemporary ceramic art.

\section{Current situation analysis}

In recent years, China's ceramic art practice has gradually participated in the construction of public space, making it popular, and gradually showing its advantages. It also broadens the channels for ceramic workers and the public to study and interact. In accordance with this, there are also many discussions and comments on public ceramics.

However, a large number of literature shows that the relevant information is not focused on the contemporary, and the logic derivation is mostly rooted in the local. Although the material use and technical innovation of public ceramic art have been clarified, the advantages and spirit of form have been summed up, and the modern positioning and future trend have been discussed. However, we must realize that the current situation of public ceramic art development in China is still not optimistic, the degree of involvement in public space is still shallow, and some objective judgments can guide the construction of public ceramic art system in China Insufficient. Therefore, it is urgent to integrate the information of the resources that keep pace with the times, combine the relevant elements, mature principles and practical application, so as to seek the guiding theory suitable for public ceramic art in China.

Public ceramic art is an important way for contemporary ceramic art to get out of the exhibition site and enter the society. Mr. Zheng Zhi, the late professor and sculptor of the former Central Academy of Arts and crafts, once called the ceramics closely combined with architectural engineering and environmental art as "great ceramics". As early as the early 1980 s, he boldly predicted that "big ceramics" would have strong vitality and broad prospects in the future in the fields of roof, underground city, urban sculpture and environmental art.

\section{Application of digitization in public ceramics}

Digital technology, in short, refers to the technology that, with the help of computers, optical cables, communication satellites and other equipment, converts various information such as pictures, texts, sounds and images into binary numbers that can be recognized by electronic computers, and then calculates, processes, stores, transmits, transmits and restores them. It has the characteristics of strong universality, good confidentiality and long-term storage. 


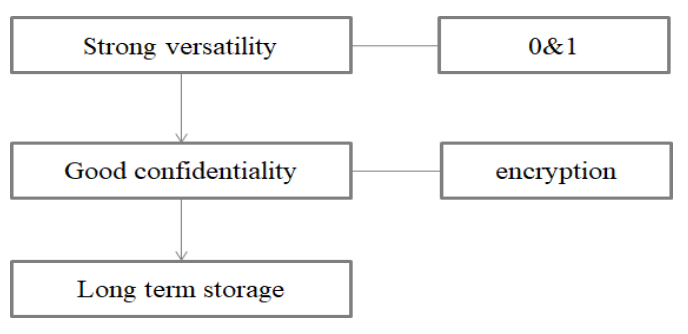

Chart 1 Characteristics of digitization

(1) Strong versatility: use simple "0" and "1" to express, transmit and process all information. At the same time, standardized logic components can be used to build various digital systems to realize information coding, compression, transmission and exchange.

(2) Good confidentiality: digital technology can encrypt various types of information resources to ensure the security and confidentiality of information resources.

(3) Long term storage: as time goes on, paper books will mildew, video tapes will be damaged and aged, and digital signals are convenient for long-term storage, so that a large number of valuable information resources can be preserved.

Based on these characteristics, digital technology is very suitable for the protection of cultural heritage. Among the emerging digital media technologies, the commonly used technologies include scanning graphics and text, three-dimensional scanning, holographic projection, digital photography, motion capture, and information storage and transmission technologies such as database, disk array and optical fiber network. Through the digital acquisition and storage technology, various types of text, image, audio and video are converted into digital format and stored in disk and $\mathrm{CD}$. Using database to manage information resources is very suitable for longterm protection and dissemination of various cultural heritage.

\section{Influence of digital application on public ceramics}

\subsection{Carry out digital modeling}

The application of 3D digital technology in ceramic industry at home and abroad has begun to be involved. In order to generate the three-dimensional graphics of ceramic products, we must first digitize the ceramic products, and then use the computer-aided geometric method to generate three-dimensional ceramic product graphics. As long as we digitize the ceramic production, we can modify it on the computer.

Three dimensional digital modeling is generally divided into several stages: project determination, project modeling, project improvement and project optimization.

(1) Project determination: the designer should communicate with customers and draw sketches.

(2) Project Modeling: designers select suitable 3D modeling software for product modeling according to the preliminary sketch. For example, rhino software is often used to make ceramic products with regular shape. ZB software is often used to make some character modeling, and fine carving software is often used to carve the surface of some products. Designers can choose the relevant modeling software according to the modeling characteristics of ceramic products and their own modeling habits.

(3) Project improvement: improve the 3D data model according to the modification opinions of customers, and then use the rendering tools such as keyshot and V-Ray to quickly render the effect according to the product modeling characteristics of different products and the needs of customers, which is very convenient for the development of subsequent products.

(4) Project optimization: the work in this stage is mainly to produce beautiful ceramic products for service, and the best scheme selected by the designer is further improved, such as the design of decorative paper for ceramic products to improve the added value of ceramic products. In the design process, the $17 \%$ shrinkage ratio between the ceramic product and the model was fully considered. In the process of modeling, the digital ceramic model should be enlarged. Then we can put the digital model into production by $3 \mathrm{D}$ printing.

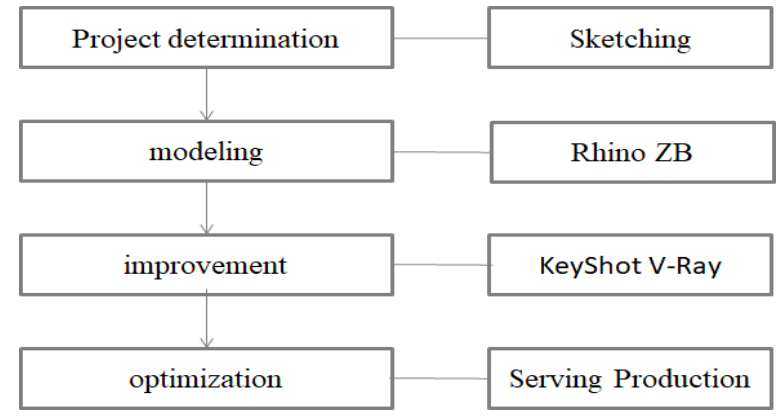

Chart 2 Digital modeling process

\subsection{Innovation of digital production process}

Ceramic manufacturing process includes the main production processes of drilling, hole filling, printing and lamination, the auxiliary processes are tearing film, laminating, leveling and scraping, and the detection process is hole detection and printing detection. At present, the domestic ceramic manufacturing process can reach: the maximum number of holes drilled on raw porcelain is 30000 , the minimum diameter of Machinable hole is $80 \mu$ $\mathrm{m}$, the minimum width of printing line is $50 \mu \mathrm{m}$, and the maximum number of laminated layers is 50 layers. The digital production line needs to have this kind of manufacturing ability and be compatible with the manufacturing process of different substrate products.

By analyzing the manufacturing process of different products, the digital ceramic production line starts from solving the most complex non film production process of substrate manufacturing. After the substrate manufacturing process Carding and redesign, combing the process path and logistics path, determining the layout of process equipment, transmission equipment and operation station, etc. the process design of production line includes all processes, and each process is optional, that is, physically connected, logically connected or disconnected. In this way, the flexible manufacturing process of each 
product and each layer of substrate can be realized. Based on this design idea, the digital ceramic production line has designed the production process of tearing film, punching, laminating, filling, printing and laminating as the main processes. Meanwhile, the entrances and exits of secondary printing, unqualified product treatment and repair parts entering into the production line are designed to meet the on-line manufacturing process requirements of multi-layer complex substrate. The manufacturing process design flow of digital ceramic production line is shown in the Chart3 below.

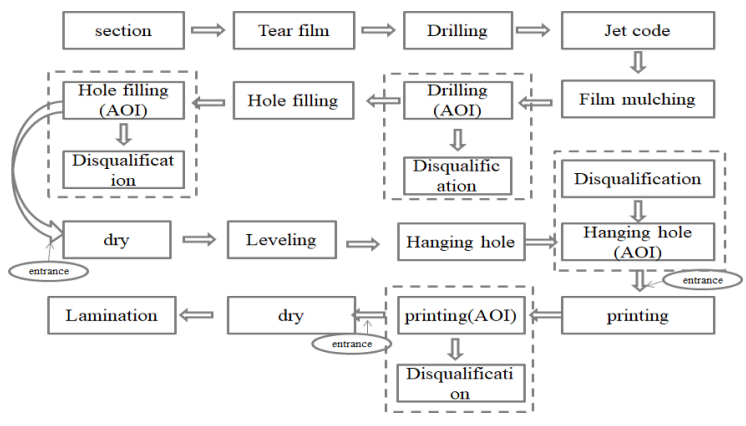

Chart 3 Digital manufacturing process

\subsection{Improve the digitalization ability of production line}

The production line needs to realize the whole line linkage control of dozens of equipment to ensure that each equipment accurately collects information, reasonably schedules production and completes orderly according to the production rhythm. Based on this control requirement, the upper control system of the production line is designed. The information interaction between the upper control system and all the equipment on the production line is bidirectional. Through the information interaction, the upper control system completes 17 processes, including 15 kinds of data acquisition and scheduling control of more than 30 sets of process equipment, detection equipment and logistics transmission equipment. Chart 4 is the schematic diagram of information interaction between the production line equipment and the upper control system.

The interactive information includes equipment data, production data, quality data and process parameters. According to the production process control requirements, the upper control system sends processing data, process parameters and processing instructions, and the equipment on the production line uploads process data, material consumption, processing status and equipment status according to the equipment status and production status.

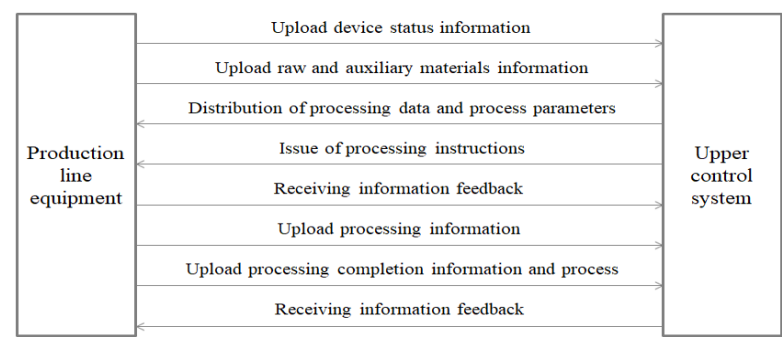

Chart 4 Schematic diagram of information interaction

The punching process section of the production line includes four categories, including film tearing machine, equipment logistics line, machine personnel streamline and drilling unit, with a total of 16 sets of equipment. As shown in Chart 5, the upper control system needs to reasonably control the scheduling equipment to complete the production task allocation.

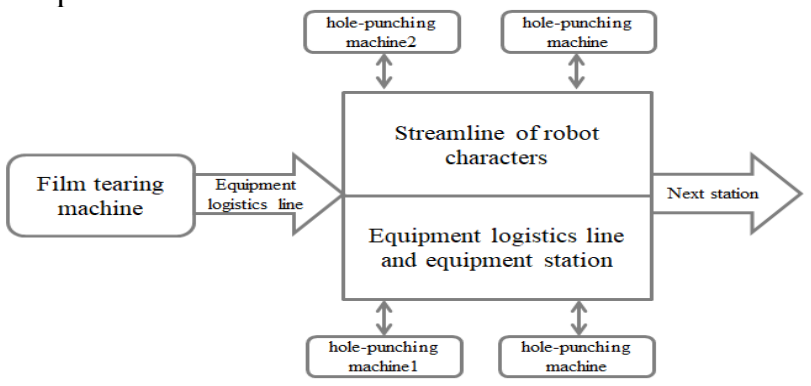

Chart 5 Physical location of equipment and logistics line

The upper control system takes the status of equipment station and punching machine as the basis of new action task of machine character streamline. When there is a workpiece in the equipment station, the upper control system adds a film placement task in the robot task list. When the drilling is completed, the upper control system adds the task of taking and sending the film to the robot task list. The upper control system queries the robot task list periodically at the same time, and sends the task instruction to the robot character streamline according to the priority principle. The instruction contains single chip serial number, task start and end point information. The robot task data is shown in Table 1 .

Table 1 Robot task data sheet

\begin{tabular}{|c|c|c|}
\hline Field name & Field type & Remarks \\
\hline ID & INT & Index number \\
\hline Location & INT & Station \\
\hline Product ID & CHAR(40) & $\begin{array}{c}\text { Workpiece serial } \\
\text { number }\end{array}$ \\
\hline Jodotype & INT & Task type \\
\hline Isfinshed & BOOL & Is it completed \\
\hline Ordernumber & CHAR(100) & Work order No \\
\hline Creatdate & DATETIME & Creation time \\
\hline
\end{tabular}




\subsection{Accelerating the digitization of ceramic printing}

In order to realize the automatic control process flow of ceramic production line, the printing machine has the functions of data interaction with upper control system, work order execution and verification, and material identification information reading and verification of raw and auxiliary production materials. Chart 6 shows the operation and control interface diagram of the printing machine.

At the beginning of production execution, the upper control system issues the corresponding screen material number and paste batch number according to the work order task, and the printer receives the relevant information. After the production preparation is completed, verify whether the actual screen plate and paste barcode information is consistent with the issued information, so as to determine whether to carry out the work order roduction. The screen material number and paste batch number of the printing process are displayed on the printing machine interface. The printing press triggers the upper control system to query the inventory table of the buffer library through the work order execution button on the interface, and writes the required work order workpiece into the intermediate table to be operated in the cache library. The upper control system successively calls the work order workpiece in the buffer library to complete the feeding for the printing machine process. Chart6 is the logic block diagram of the upper control system for the printing press scheduling control.

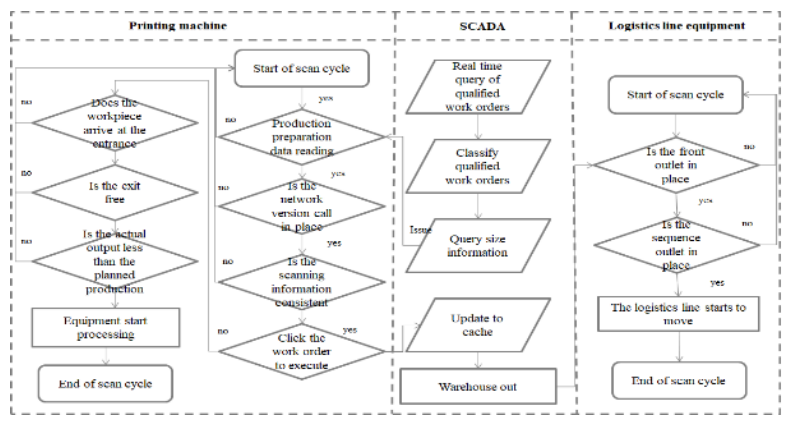

Chart6 Logic diagram of production line interactive control

\section{5 conclusion}

Digital application in the field of public ceramics has become increasingly mature, which has a profound impact on the modeling, production process, process and ceramic printing of public ceramics. The application of threedimensional digital modeling technology makes the ceramic production mode become diversified, which can easily produce irregular ceramic works. The application of rendering technology can first present the ceramic products to be produced with computer three-dimensional digital technology, so that the customers can determine and then carry out the ceramic production, which changes the disadvantages of the traditional ceramic samples that can be confirmed by customers, saving a lot of resources. Through the research of modeling technology in ceramic production, the design of ceramic products is attached with flying wings. The development of 3D digital modeling technology accelerates the development of ceramic manufacturing industry towards "intelligent". It provides a broader space for the development of ceramic product design, and accelerates the diversification of ceramic product design.

\section{Acknowledgment}

This study was supported by Research on the application of architectural pattern elements in public art design in South Fujian, June 2020, guiding college students' innovation training project (national level), Project No.: 202013115009, and Research on Fujian Provincial New Engineering, New Agricultural Science Research and Reform Practice Project, Project Host ,jiao Gao (2020)4, and Research on the development countermeasures of tourism, cultural and creative industry in Western Fujian under the guidance of "digital creative industry", youth social science project of Fujian Provincial Department of education, Project No.: jas19350 / a201919, and Research on Fujian University Architecture Specialty Innovation and Entrepreneurship Education Reform pilot Professional Construction Project, Fujian Education High (2017)27, and Research on Fujian University Civil Engineering Applied discipline Construction Project, Minjiao Gao (2017)44, and Research on Fujian University Construction and Civil Engineering Applied Specialty Group pilot Construction Project, Minjiao Gao (2017)34.

\section{References}

1. Recuero S, N. Andrés, Lobera J, et al. Application of DSPI to detect inhomogeneous heating on superconducting ceramics [J]. Measurement ence \& Technology, 2005, 16(4):1030-1036.

2. Chenoweth K, Duin A C T V, Goddard W A I . The ReaxFF Monte Carlo Reactive Dynamics Method for Predicting Atomistic Structures of Disordered Ceramics: Application to the Mo3VOx Catalyst [J]. Angewandte Chemie International Edition, 2010, 48(41): 7630-7634.

3. Kibuuka G, Bertenburg R, Naghed M, et al. Coplanar Lumped Elements and their Application in Filters on Ceramic and Gallium Arsenide Substrates[C]// European Microwave Conference. IEEE,2007.

4. Y, Belrhiti, and, et al. Application of optical methods to investigate the non-linear asymmetric behavior of ceramics exhibiting large strain to rupture by fourpoints bending test[J].Journal of the European Ceramic Society, 2012.

5. Eva, Vejmelková, Tereza, et al. Application of Waste Ceramics as Active Pozzolana in Concrete Production[C]// 2012 International Conference on Digital Convergence (ICDC 2012). 0.

6. Soudarev A V, Souryaninov A A, Grishaev V V, et al. Ceramic Gas-Turbine 2.5 MW Engine for Gas Industry Application in Russia[C]// Asme Turbo Expo: Power for Land, Sea, \& Air. 2000. 
7. Cui J, Zhang X, Liu H, et al. Preparation and application of zeolite/ceramic microfiltration membranes for treatment of oil contaminated water[J]. Journal of Membrane ence, 2008, 325(1):420-426.

8. Cui, Jiaoying, et al. "Preparation and application of zeolite/ceramic microfiltration membranes for treatment of oil contaminated water." Journal of Membrane ence 325.1(2008):420-426. 